\title{
TLIF-MIS VS TLIF-OPEN: COST EVALUATION
}

\author{
TLIF-MIS VS TLIF-OPEN: EVALUAÇÃO DE CUSTOS \\ TLIF MIS VS TLIF-OPEN: EVALUACIÓN DE COSTOS \\ luis Muñiz luna ${ }^{1}$, Rodolfo Echeagaray Sánchez ${ }^{2}$, Marco Antonio Marbán Heredia ${ }^{2}$, Karen Aida Ibarra Stone ${ }^{3}$, Erika Silva Chiang ${ }^{2}$. \\ 1. "Hospital deTraumatología y Ortopedia Lomas Verdes", Edo. de México Poniente, Instituto Mexicano del Seguro Social, Mexico. \\ 2. UMAE HTOLV, IMSS, Mexico. \\ 3. Medical Doctor, Clinical Research Methodology Advisor, Mexico.
}

\begin{abstract}
Objective: To evaluate the direct costs of transforaminal lumbar interbody fusion (TLIF) and minimally invasive surgery (MIS) or open technique (OPEN). Methods: The present study is descriptive and retrospective. Sixteen patients with degenerative spinal pathology operated on with the TLIF MIS technique and TLIF OPEN were included over a 13-month period. Days of hospital stay, blood loss, surgical time, medical care and costs were compared. Results: The mean number of days of hospital stay was $6.7 \pm 4.3$ days with TLIF MIS and $11.1 \pm 6.5$ days with TLIF OPEN. The blood loss was $307 \pm 81.6 \mathrm{ml}$ (range $200-$ $400 \mathrm{ml}$ ) with TLIF MIS and $803 \pm 701.3 \mathrm{ml}$ (range 200-1800 ml) with TLIF OPEN. The surgical time was $320 \pm 92.6 \mathrm{minutes}$ (range 210-500 minutes) in TLIF MIS and $372 \pm 95.2$ minutes (280-540 minutes) in TLIF OPEN. Conclusions: The difference in surgical costs and time between the two procedures was not statistically significant. There was less bleeding during the TLIF-MIS surgery, as well as a correlation between shorter days of hospital stay proportional to bleeding and surgical time, which translates into a reduction in the cost of these items. Level of Evidence III; Analysis based on alternatives and limited costs.
\end{abstract}

Keywords: Intervertebral disc degeneration; Spinal fusion; Arthrodesis.

\section{RESUMO}

Objetivo: Garantir benefícios econômicos diretos de cada procedimento cirúrgico. Metodologia: apresentar um estudo descritivo e retrospectivo. Dezesseis pacientes com patologia degenerativa de colônias operados com a técnica TLIF MIS e TLIF OPEN foram incluídos durante um período de 13 meses. Foram comparados os dias de internação, perda de sangue, tempo cirúrgico, assistência médica e custo. Resultados: O número de dias hospitalares para 6,7 \pm 4,3 dias no TLIF MIS e 11,1 \pm 6,5 dias no TLIF OPEN. Quanto à diferença entre a exigência de resultados da imagem e o número de cirurgias. A perda de sangue foi de $307 \pm 81,6 \mathrm{ml}$ (intervalo de 200-400 ml) com TLIF MIS e $803 \pm 701,3 \mathrm{ml}$ (intervalo de $200-1800 \mathrm{ml}$ ) com TLIF OPEN. O tempo cirúrgico de $320 \pm 92,6$ minutos (intervalo 210-500 minutos) em TLIF MIS e $372 \pm 95,2$ minutos (280-540 minutos) em TLIF OPEN. Conclusões: A diferença entre os procedimentos cirúrgicos e o tempo entre os procedimentos não é estatisticamente significativa. Houve menos sangria durante a cirurgia do TLIF-MIS, assim como uma correlação entre menos dias de internação proporcional ao sangramento e ao tempo cirúrgico, que se traduziu em uma redução dos custos dos itens. Nível de Evidência III; Análise baseada em alternativas e custos limitados.

Descritores: Degeneração do disco intervertebral; Fusão vertebral; Artrodese.

\section{RESUMEN}

Objetivo: Evaluar los costos directos de la fusión intersomática lumbar transforaminal (TLIF) de mínima invasión (MIS) o técnica abierta (OPEN). Métodos: El presente estudio es descriptivo y retrospectivo. Se incluyeron 16 pacientes con patología degenerativa de columna intervenidos con la técnica TLIF MIS y TLIF OPEN en un período de 13 meses. Se compararon días de estancia hospitalaria, pérdida sanguínea, tiempo quirúrgico, atención médica y costos. Resultados: La media de días de estancia hospitalaria fue de 6,7 \pm 4,3 días con TLIF MIS y de 11,1 \pm 6,5 días con TLIF OPEN. La pérdida sanguínea fue de 307 \pm 81,6 ml (rango 200-400 $\mathrm{ml}$ ) con TLIF MIS y de $803 \pm 701,3 \mathrm{ml}$ (rango 200-1800 ml) con TLIF OPEN. El tiempo quirúrgico fue de $320 \pm 92,6 \mathrm{minutos}$ (rango 210-500 minutos) en TLIF MIS y de $372 \pm 95,2$ minutos (280-540 minutos) en TLIF OPEN. Conclusiones: La diferencia de costos y tiempo quirúrgico entre ambos procedimientos no fue estadísticamente significativa. Se mostró un menor sangrado durante la cirugía TLIF-MIS, así como una correlación entre menores días de estancia hospitalaria proporcional con el sangrado y tiempo quirúrgico, lo cual traduce una reducción del costo en esos rubros. Nivel de Evidencia III; Análisis basados en alternativas y costos limitados.

Descriptores: Degeneración del disco intervertebral; Fusión vertebral; Artrodesis. 


\section{INTRODUCTION}

Degenerative spine disease is one of the most common comorbidities in elderly patients, triggering discogenic back pain and spinal instability. ${ }^{1}$ Lumbar fusion is used to manage spinal deformity and instability, with the objective of achieving segmental arthrodesis with adequate disc height, vertebral alignment, and decompression of the neurological structures. ${ }^{2}$

Transforaminal Lumbar Interbody Fusion (TLIF) is one of the surgical options used for the stabilization and treatment of degenerative lumbar diseases such as degenerative discopathy and spondylolisthesis that do not respond to conservative management. ${ }^{1}$

Since Harms and Rolinger first described the procedure in 1982, OPEN TLIF has allowed circumferential arthrodesis and restoration of disc height, with a fusion rate of $95 \%$, and has been considered a safe and effective option for the past 30 years. ${ }^{3,4}$

The TLIF OPEN surgical technique consists of a standard incision in the midline with subperiosteal exposure of the musculature, exposing the facet joint complex to the distal space that is being fused in its entirety. A unilateral facetectomy is performed with the placement of an interbody cage and bilateral fixation with transpedicle screws. This can be accompanied by central decompression. The bone graft, obtained locally by facetectomy or laminectomy, is placed inside the interbody cage. ${ }^{5}$ However, the extensive dissection and retraction of paravertebral muscle during the procedure to achieve adequate vision of the surgical field causes significant damage to the soft tissues. This iatrogenic damage causes blood loss, postoperative pain, paravertebral muscle atrophy, and a prolonged hospital stay. ${ }^{4}$

In order to avoid these inconveniences, and especially to preserve the paravertebral musculature, the minimally invasive TLIF (MIS TLIF) technique was introduced and has become an increasingly popular technique. ${ }^{6}$ To minimize the adverse effects of the open technique, Foley et al. described the MIS TLIF technique for the first time, performed via a tubular retraction system and significantly reducing tissue injury.

To carry out the MIS TLIF technique, a unilateral approach using the Wiltse approach is performed under fluoroscopic vision. Unilateral pedicle screws are placed percutaneously with the placement of a guidewire. The laminectomy, the bilateral decompression, and the lumbar interbody fusion are performed through a non-expandable $21 \mathrm{~mm}$ tubular dissector. The paravertebral musculature and the ligament complex are preserved during the procedure. The bone graft, obtained locally by facetectomy or laminectomy, is placed inside the interbody cage. ${ }^{5}$

Despite the advantages associated with MIS TLIF, there are certain disadvantages, such as the visibility and the limited surgical field that require the surgeon to have adequate familiarity with the anatomy, as well as the prolonged surgical time and exposure to radiation from prolonged use of the fluoroscope.

Both the open and minimally invasive techniques have shown to be effective and safe procedures for managing lumbar spine pathology. There is concern regarding the costs associated with performing minimally invasive procedures. Theoretically, the advantages that result from this procedure should be lower perioperative costs.

The most studied variables are:

Blood loss: It has been shown that there is much less transoperative blood loss from the MIS TLIF technique than from the OPEN TLIF technique. Variations of $100 \mathrm{ml}$ (MIS TLIF) versus 450 $\mathrm{ml}$ (OPEN TLIF) and $456 \mathrm{ml}$ versus $951 \mathrm{ml}$, respectively, have been documented, ${ }^{7,8}$ as well as $77 \mathrm{ml}$ (MIS TLIF) versus $461 \mathrm{ml}$ (OPEN TLIF), $124 \mathrm{ml}$ in MIS TLIF versus $295 \mathrm{ml}$ in OPEN TLIF, $200 \mathrm{ml}$ in MIS TLIF versus $296 \mathrm{ml}$ in OPEN TLIF, 124.4 in MIS TLIF versus 380.3 $\mathrm{ml}$ in OPEN TLIF, and $50.6 \mathrm{ml}$ in MIS TLIF versus 447.4 in OPEN TLIF. ${ }^{1,2,5,9}$ A total of 22 studies have shown a significant difference with an interval of $256 \mathrm{ml}$ between MIS TLIF and OPEN TLIF, being significantly less with the minimally invasive technique. ${ }^{10}$

Surgical time: In some cohort studies times are reported without a significant difference, such as 185 minutes in MIS TLIF versus 186 minutes in OPEN TLIF, and 166.4 minutes in MIS TLIF versus 181.1 in OPEN TLIF.1,2 However, in other studies there are marked differences between the surgical times, such as 216.4 minutes in MIS TLIF versus 170.5 minutes in OPEN TLIF. Brodano et al. reported similar results with 2.4 hours for MIS TLIF versus 1.7 hours for OPEN TLIF, as well as 300 minutes versus 210 minutes for MIS TLIF and OPEN TLIF, respectively, and 186.0 minutes versus 115.8 minutes for MIS TLIF and OPEN TLIF., $5,9,11$ Several studies reported inverted results with 161 minutes for MIS TLIF versus 227.4 minutes for OPEN TLIF, however, because of the heterogeneity detected, the difference was not significant. ${ }^{12}$

Hospital stay: In most studies, the duration of the hospital stay for patients who underwent MIS TLIF was significantly shorter than OPEN TLIF, 4.7 days for MIS TLIF versus 8 days for OPEN TIF, as well as a difference of 1 day between MIS TLIF and OPEN TLIF, 3 days for MIS TLIF versus 5 days for OPEN TLIF, 6.1 days versus 8.2 days for MIS TLIF versus OPEN TLIF, respectively, and 3.2 days for MIS TLIF versus 6.8 days for OPEN TLIF, ${ }^{1,2,8,9} \mathrm{~A}$ total of 18 studies reported a significant difference with a decrease of 1.3 days between MIS TLIF and OPEN TLIF. ${ }^{13}$

Exposure to radiation: Most studies report higher exposure to radiation in MIS TLIF, ranging from 45.3 to 106 seconds as compared to 24-39 seconds for OPEN TLIF. Another study showed a difference of 37 seconds longer in MIS TLIF than in the OPEN TLIF procedure, as well as an average of 17.6 seconds for the open technique versus 49.0 seconds for the minimally invasive technique., ${ }^{1,2,11}$ A total of 8 studies analyzed the two techniques, reporting a significant difference of 38.2 seconds between MIS TLIF and the open technique, ranging from 49-106 seconds with MIS TLIF versus 16.5-44 seconds with OPEN TLIF, ${ }^{3,10}$ One study reported a significant difference in exposure to radiation of $2.7 \mathrm{cGy} / \mathrm{cm}^{2}$ for MIS TLIF and $1.8 \mathrm{cGy} / \mathrm{cm}^{2}$ for OPEN TLIF. ${ }^{8}$ In a meta-analysis, 8 cohort studies were identified with a total of 619 patients. The time of exposure to the fluoroscope during an OPEN TLIF was 39.42 seconds and 94.21 seconds for MIS TLIF.

Complications and reinterventions: The rate of complications varies from $0.6 \%$ to $31.6 \%$ in cases of MIS TLIF versus $9.5 \%-52 \%$ with OPEN TLIF. Equality is reported in the case of tearing of the dura mater without significant difference, as well as for the improper positioning of the graft, poor screw placement, neurological deficit, hematoma, delayed consolidation, and leakage of cerebrospinal fluid, but the presence of infection was $2 \%$ versus $4.6 \%$ for MIS TLIF and OPEN TLIF, respectively. ${ }^{1,11}$ Complication rates of $8.1 \%$ in MIS TLIF versus $16.2 \%$ in the open technique have been reported, evaluating the incidence of infection of the wounds, poor implant position, leakage of cerebrospinal fluid, urinary tract infection, and mild neurological deficit. ${ }^{12}$ One study reported a more serious complication in the open technique (myocardial infarction) and in MIS TLIF (poor screw placement requiring revision surgery) and two lesser complications for each (OPEN: pneumonia and postoperative anemia; MIS: pneumonia and incidental durotomy). ${ }^{2}$ A total of 25 studies extracted sufficient data, with the total number of complications resulting in a relative risk of $0.65 \%$ when comparing MIS TLIF versus OPEN TLIF with a confidence interval of 95\% from 0.50 to $0.83(\mathrm{P}<0.001) .{ }^{10}$ Eight studies reported a higher reintervention rate in cases of MIS TLIF, but it is not statistically significant, associating greater failure in graft placement and fusion with MIS TLIF and a higher rate of incidental durotomy and infection of the surgical wound in OPEN TLIF. ${ }^{14}$ One study divides the complications into technical, infectious, and systemic. The technical and infectious complications include incidental durotomy, poor screw placement, and infection of the wound. The systemic complications include pneumonia, urinary tract infection, and deep vein thrombosis. The number of patients with complications was 54 out of $455(11.87 \%)$ in MIS TLIF versus 64 out of 446 (14.35\%) in OPEN TLIF. ${ }^{3}$

Costs: The direct hospital costs for each study were lower in MIS TLIF than in OPEN TLIF, associated with less blood loss, fewer days in the hospital, and fewer complications. ${ }^{12} \mathrm{~A}$ financial analysis of the total direct hospital costs (blood, imaging, implant, drugs, physical/occupational or speech therapy, hospital stay) were lower in MIS TLIF than in OPEN TLIF, at USD 19,512 versus USD 23,550, respectively. The cost of the implants was similar. The hospital was 
paid USD 6,248 more for OPEN TLIF than for MIS TLIF. ${ }^{5}$ A faster return to work was reported with the MIS TLIF technique at 8.5 weeks versus 17.1 weeks for OPEN TLIF, which translates into a reduction of the indirect costs related to work disability associated with TLIF procedures. ${ }^{15}$ In nine studies, the results of the economic evaluations showed costs/hospital charges in the MIS TLIF cohorts with a wide range of $2.5 \%$ to $49.3 \%$. In 2001, Rampersaud et al. calculated one year of cost-utility using the direct hospital costs and one-year costs for quality of life adjustments, yielding USD 128,936 with MIS TLIF versus USD 232,912 with the open technique. Parker et al. included both direct and indirect costs in an evaluation of the cost-utility in two years of MIS technique and open technique. They found that the cost for quality of life adjustment per year is USD 50,017 with the MIS technique compared to USD 68,860 for the open technique. ${ }^{16}$

The MIS TLIF technique is a viable alternative, without any difference in the fusion rate or in the Oswestry functionality scale or the VAS for pain in follow-ups. The most marked advantages of the MIS TLIF are lower trans-surgical blood loss, shorter hospital stay, and faster return to work. ${ }^{13,14}$ This reflects a reduction in the direct and indirect hospital costs. However, there is a tendency towards longer surgical time and greater exposure to radiation. ${ }^{5,12,15-19}$

\section{METHODS}

The medical records of 16 patients with degenerative spine pathology were reviewed, 9 who were operated using the MIS TLIF technique and 7 with the OPEN TLIF technique over a period of 13 months. The clinical records met the following criteria: patients who underwent $360^{\circ}$ lumbar arthrodesis using the MIS TLIF technique with the placement of a system of transpedicle screws and an interbody cage or OPEN TLIF with the placement of transpedicle screws and an interbody cage using the open technique during the period from January 2016 to February 2017. Length of hospital stay in days (LOS), number of surgeries, laboratory exams conducted, consultations with specialists (not including orthopedic consultations), radiographs, Computed Axial Tomography (CAT), Magnetic Resonance Imaging (MRI), ambulance transfers, days in the Intensive Care Unit (ICU), outpatient orthopedic consultations, neuromonitoring, bleeding, surgical time, and costs were compared between both surgical techniques. In the statistical analysis, the categorical variables were expressed as frequencies and percentages (\%). The quantitative variables were expressed as averages, ranges, \pm SD. The Student's T test was used for their comparison and $p<0.05$ was considered statistically significant. To make an association between bleeding, surgical time, and LOS, the Pearson correlation coefficient was used. This study is retrospective, descriptive, observational, and non-interventionist, so it did not need to be reviewed by the Institutional Review Board, nor did it require informed consent. This research study is safe and considered to be of low to minimum risk according to the norm that establishes the provisions for health research of the Instituto Mexicano del Seguro Social. All the data obtained were used solely by the research team in order to protect the confidentiality and identity of the patients.

\section{RESULTS}

\section{Demographics}

A total population of 16 patients, 9 (56\%) who underwent surgery with the MIS TLIF technique and 7 (44\%) with the OPEN TLIF technique. Of the 9 patients with MIS TLIF, 3 (33\%) were male with an average age of $50 \pm 12$ years (ranging from 36-61 years of age) and 6 (66\%) were female with an average age of $56 \pm 8.3$ years (ranging from $45-67$ years of age). In the OPEN TLIF group $3(42 \%)$ patients were male with an average age of $55 \pm 8$ years (ranging from 46-60 years of age) and 4 (57\%) were female with an average age of $57 \pm 14$ years (ranging from $42-76$ years of age). A comparison between the sexes resulted in a significant difference between men and women $(p=0.01)$, without a significant difference in the age of the patients.

\section{Surgical procedure}

Blood loss was calculated as $307 \pm 81.6 \mathrm{ml}$ (range 200-400 ml) in MIS TLIF and as $803 \pm 701.3 \mathrm{ml}$ (range 200-1800 ml) in OPEN TLIF. The average surgical time was $320 \pm 92.6$ minutes (range 210-500 minutes) in the MIS TLIF group and $372 \pm 95.2$ minutes (280-540 minutes) in OPEN TLIF. In comparing the number of surgeries performed for each of the procedures, no statistical significances were observed $(p=0.3)$. In the correlation between the quantity of blood and the surgical time, no statistical significance was observed in either procedure, with $\rho=0.7$ in MIS TLIF and $\rho=0.08$ in OPEN TLIF (see Figures 1 and 2).

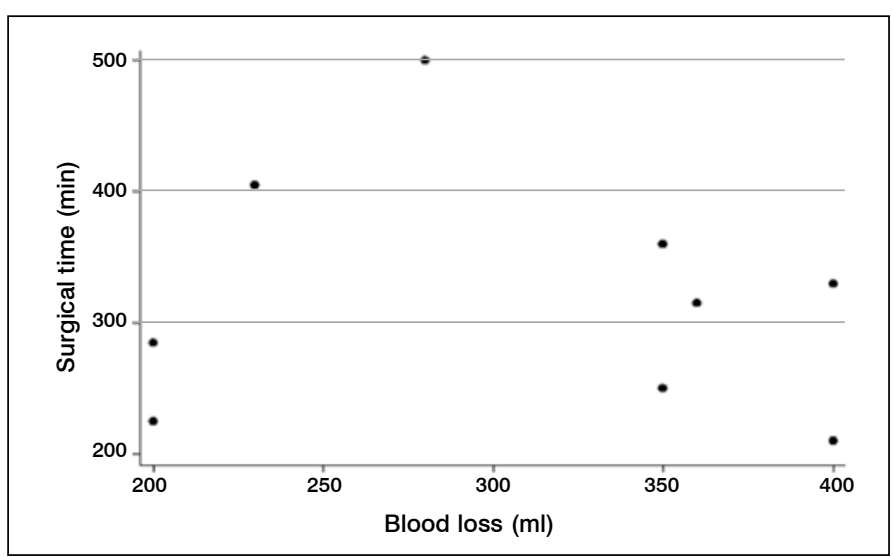

Figure 1. Correlation between bleeding and total surgical time with the MIS TLIF technique.

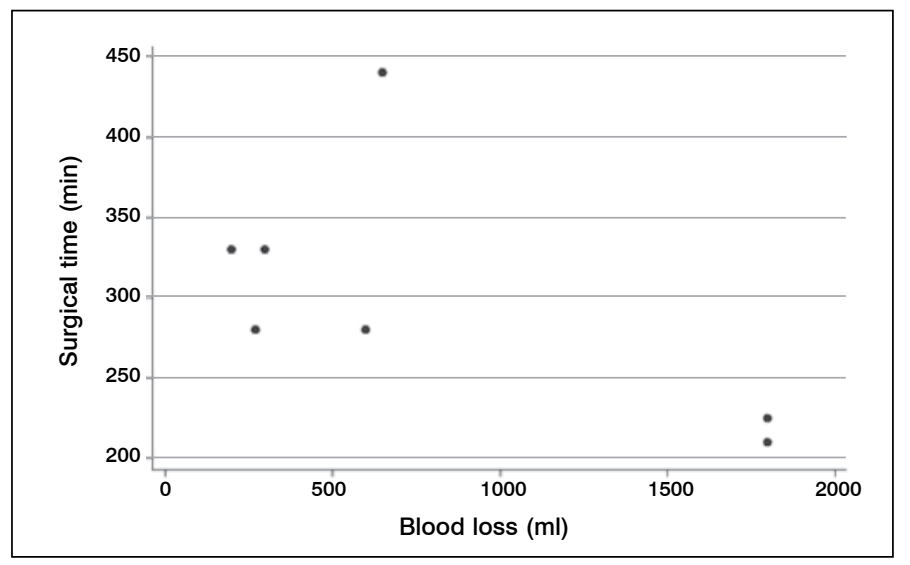

Figure 2. Correlation between bleeding and total surgical time with the OPEN TLIF technique.

\section{Hospital Costs}

The average days in the hospital was lower in the MIS TLIF group with a total of $6.7 \pm 4.3$ days and $11.1 \pm 6.5$ days with OPEN TLIF without any statistically significant difference. By associating the number of days in the hospital with the quantity of bleeding and with the surgical time in both procedures, an $r=1$ was obtained (see Figures 3 and 4).

In the MIS TLIF group, eight patients (88\%) received one specialty consultation, while in the OPEN TLIF group, 3 patients (42\%) received 4 specialty consultations, 3 patients (42\%) received one specialty consultation, and one patient (14\%) received 5 consultations.

A comparison of the imaging studies performed for both procedures did not yield any significant results. All patients required an ambulance for their transfer.

Trans-surgical neuromonitoring was used for all patients in the MIS TLIF group. The average number of outpatient consultations was $5.2 \pm 1.9$ for MIS TLIF and $7.1 \pm 1.9$ for OPEN TLIF with no significant difference. 


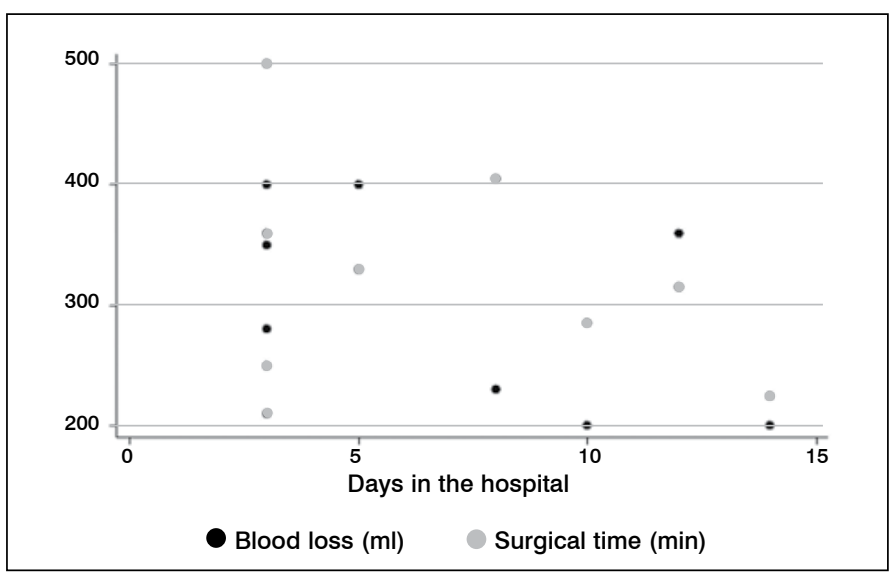

Figure 3. Correlation between bleeding and total surgical time and days in the hospital with MIS TLIF.

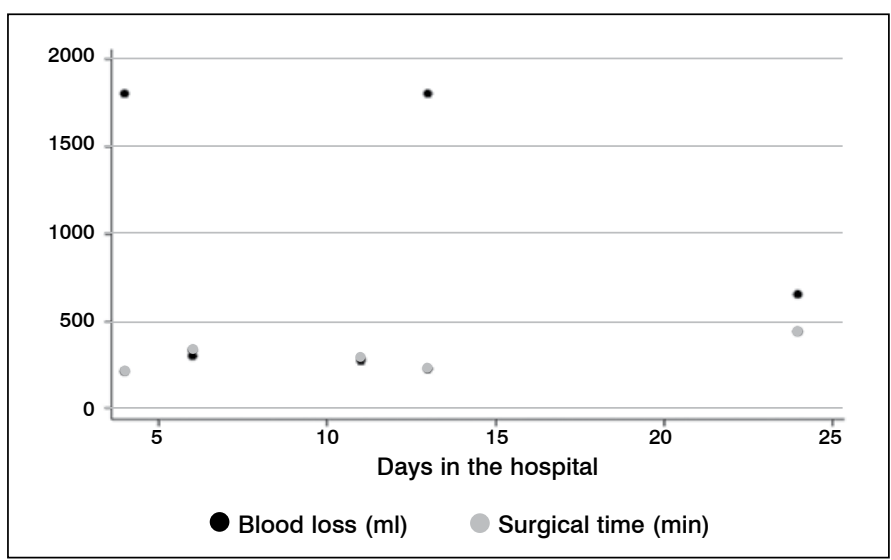

Figure 4. Correlation between bleeding and total surgical time and days in the hospital with OPEN TLIF.

\section{Cost evaluation}

In the MIS TLIF group, the average cost per patient was USD $11,593 \pm 2,240$ and for the OPEN TLIF group was 10,734 $\pm 3,036$ USD, with no statistically significant difference.

Correlating the cost and the days in the hospital, we obtained $\rho=0.002$ in both procedures. The radiography, tomography, and the number of consultations had a significant impact on the cost of the MIS TLIF group, $\rho=0.02, \rho=0.001, \rho=0.04$, respectively, which was not observed in OPEN TLIF, with the exception of magnetic resonance $(\rho=0.02)$ (See Table 1). Similarly, neuromonitoring together with the ambulances showed a positive correlation with the cost of both procedures.

\section{DISCUSSION}

The MIS TLIF technique has been associated with less blood loss. Singh et al. and Khan et al. reported wide variations in blood loss, being always less in the MIS TLIF technique than in OPEN TLIF. Lin et al. reviewed 22 studies in their meta-analysis and reported a significant difference of $256 \mathrm{ml}$ less blood loss in MIS TLIF versus OPEN TLIF. The results of our study show less blood loss in the MIS TLIF technique than in OPEN TLIF, but in is a minimal difference that is not statistically significant. When we correlated blood loss with surgical time, we obtained statistical significance.

In our study, surgical time was shorter for the MIS TLIF technique without a significant difference, which coincided with Vazan and Phan's meta-analysis, in which no significant difference was observed. Weis et al. reported surgical time ranging from 116 to 390 minutes for MIS TLIF and from 102 to 365 minutes for OPEN TLIF. Tian et al. concluded that the longer surgical time of MIS TLIF is due
Table 1. Correlation of medical care and cost with MIS TLIF and OPEN TLIF. Values of $p$ obtained using the Spearman correlation. A $p \leq 0.05$ was considered significant.

\begin{tabular}{c|c|c}
\hline \multicolumn{3}{c}{ Medical care and cost in minimally invasive and open TLIF. } \\
\hline & MIS TLIF & Open TLIF \\
\hline Days in the hospital & 0.002 & 0.002 \\
\hline Number of surgeries & 0.07 & 0.2 \\
\hline Total bleeding (ml) & 0.9 & 0.3 \\
\hline Total surgical time & 0.3 & 0.7 \\
\hline Laboratory tests & 0.8 & 0.09 \\
\hline Radiographs & 0.02 & 0.5 \\
\hline CT & 0.001 & 0.1 \\
\hline MRI & 0.1 & 0.02 \\
\hline Number of consultations with specialists & 0.1 & 0.1 \\
\hline Number of external consultations & 0.04 & 0.3 \\
\hline
\end{tabular}

to the limited work space and the greater technical demand of the procedure, with the existence of a learning curve for its realization. Lee et al. report a shorter surgical time for MIS TLIF with an average difference of 15.4 minutes between the procedures, without statistical significance.

In most studies, the length of the patient's hospital stay with the MIS TLIF technique was significantly shorter. Tian et al. reported a difference of 2.7 days, while $\mathrm{Hu}$ et al. observed a range of between 1.3 and 10.6 days. Lin et al. analyzed 18 studies reporting a significant difference of 1.3 days less for MIS TLIF. In our study there were fewer days in the hospital with the MIS TLIF technique when compared with OPEN TLIF, though not statistically significant, but when performing a correlation, it was determined that they contributed significantly to the costs of both procedures.

Phans et al. in their systematic review of 6 studies about the economic evaluation comparing MIS TLIF and OPEN TLIF showed a decrease in direct hospital costs in the MIS TLIF group with a statistically significant difference. Parker et al. followed 30 patients for two years, 15 of whom belonged to the MIS TLIF group and 15 to the OPEN TLIF group. The total cost was less for MIS TLIF, but the difference was not statistically significant. Singh et al. did a financial analysis of the total direct hospital costs (blood, imaging, implants, physical/occupational or speech therapy, hospital stay) of 33 MIS TLIF and 33 OPEN TLIF patients that showed MIS TLIF to be less expensive than OPEN TLIF. The results of our study show that there is a difference in costs between the two techniques, MIS TLIF being higher, but without a statistically significant difference. However, the use of neuromonitoring for the whole MIS TLIF group contributed to the increased costs. In correlating the costs of the MIS TLIF group and neuromonitoring, $r=1$ was obtained.

The main limitations of this study are the size of the sample and the fact that the number of patients is not proportional between the two procedures. Naturally, it is not possible to conduct a cost/benefit analysis in a retroactive cohort study, so it would be interesting to follow-up on these patients to know with greater certainty which procedure is better.

\section{CONCLUSIONS}

The fact that the MIS TLIF technique requires a learning curve and is more demanding technically and in terms of surgical time needs to be considered. Although there is no statistical significance between blood loss and surgical time in the MIS TLIF group, there was a positive correlation between these two parameters, from which we conclude that the greater the mastery of the technique, the shorter the surgical time and the less the resulting blood loss. Because all the patients in the MIS TLIF group received neuromonitoring, a direct dependence on the total cost was shown with an increase of $8 \%$ in the total value. 
We can conclude that the number of days in the hospital, the use of transoperative neuromonitoring, the use of ambulances, and studies to corroborate the diagnosis such as CAT and/or MRI are the factors that most increase the costs of said procedures.

It is important to report the time of trans-surgical exposure to radiation, which was shown to be higher with the MIS TLIF technique, this being a disadvantage for the surgeon and surgical personnel.

Despite previous studies, in our population the difference in costs and surgical time between the procedures was not statistically significant.
Studies with a greater number of patients with long-term follow-up are required to be able to compare the advantages and indirect costs, such as return to work, the need for physical therapy and changes to the structure of the home, between the two surgical techniques.

All authors declare no potential conflict of interest related to this article.

CONTRIBUTION OF THE AUTHORS: Each author made significant individual contributions to this manuscript. LM (0000-0003-2363-5589)* and RE (0000-0001-9153-6916)* were the main contributors to the preparation of the manuscript. RE reviewed the clinical records of the patients and collected the data. MA (0000-0002-0718-5445)* documented the cases in the clinical records. KA (0000-0003-0204-1335)* developed the statistical design. LM, RE, ES (0000-0002-6480-1128)*, and KA evaluated the statistical analysis data. RE and MA performed the bibliographical research. LM and ES conducted the final review of the manuscript and contributed to the intellectual concept of the study. ${ }^{*}$ ORCID (Open Researcher and Contributor ID).

\section{REFERENCES}

1. Vazan M, Gempt J, Meyer B, Buchmann N, Ryang YM. Minimally invasive transforaminal lumbar interbody fusion versus open transforaminal lumbar interbody fusion: a technical description and review of the literature. Acta Neurochir (Wien). 2017;159(6):1137-1146.

2. Phan K, Rao PJ, Kam AC, Mobbs RJ. Minimally invasive versus open transforaminal lumbar interbody fusion for treatment of degenerative lumbar disease: systematic review and meta-analysis. Eur Spine J. 2015;24(5):1017-1030.

3. Phan K, Hogan JA, Mobbs RJ. Cost-utility of minimally invasive versus open transforaminal lumbar interbody fusion: systematic review and economic evaluation. Eur Spine J. 2015;24(11):2503-13.

4. Christensen $A$, Høy K, Bünger $C$, Helming $P$, Hansen ES, Andersen $T$, et al. Transforaminal lumbar interbody fusion vs. posterolateral instrumented fusion: cost-utility evaluation along side an RCT with a 2-year follow-up. Eur Spine J. 2014;23(5):1137-43.

5. Parker SL, Adogwa O, Bydon A, Cheng J, Mcgirt MJ. Cost-Effectiveness of Minimally Invasive versus Open Transforaminal Lumbar Interbody Fusion for Degenerative Spondylolisthesis Associated Low-Back and Leg Pain Over Two Years. World Neurosurg. 2012;78(1-2):178-84

6. Schizas C, Tzinieris N, Tsiridis E, Kosmopoulos V. Minimally invasive versus open transforaminal lumbar interbody fusion: evaluating initial experience. Int Orthop. 2008;33(6):1683-8

7. Peng CWB, Yue WM, Poh SY, Yeo W, Tan SB. Clinical and Radiological Outcomes of Minimally Invasive Versus Open Transforaminal Lumbar Interbody Fusion. Spine. 2009;34(13):1385-9.

8. Singh K, Nandyala SV, Marquez-Lara A, Fineberg SJ, Oglesby M, Pelton MA, et al. A perioperative cost analysis comparing single-level minimally invasive and open transforaminal lumbar interbody fusion. Spine J. 2014;14(8):1694-701.

9. Khan NR, Clark AJ, Lee SL, Venable GT, Rossi NB, Foley KT. Surgical Outcomes for Minimally Invasive vs Open Transforaminal Lumbar Interbody Fusion. Neurosurgery. 2015;77(6):847-74.

10. Lin Y, Chen W, Chen A, Li F. Comparison between Minimally Invasive and Open Transforaminal Lumbar Interbody Fusion: A Meta-Analysis of Clinical Results and Safety Outcomes. J Neurol Surg A Cent Eur Neurosurg. 2015;77(1): 2-10.
11. Tian NF, WuYS, Zhang XL, Xu HZ, ChiYL, Mao FM. Minimally invasive versus open transforaminal lumbar interbody fusion: a meta-analysis based on the current evidence. Eur Spine J. 2013;22(8):1741-9.

12. Hu W, Tang J, Wu X, Zhang L, Ke B. Minimally invasive versus open transforaminal lumbar fusion: a systematic review of complications. Int Orthop. 2016;40(9):1883-90.

13. Lin Y, Chen W, Chen A, Li F. Comparison between Minimally Invasive and Open Transforaminal Lumbar Interbody Fusion: A Meta-Analysis of Clinical Results and Safety Outcomes. J Neurol Surg A Cent Eur Neurosurg. 2016;77(1):2-10.

14. Assaker R, Zairi F, Allaoui M. Minimally Invasive Transforaminal Lumbar Interbody Fusion (TLIF): Indications and Techniques. In: Pinheiro-Franco JL, Vaccaro AR, Benzel EC, Mayer M (eds). Advanced Concepts in Lumbar Degenerative Disk Disease. Berlim: Springer-Verlag Berlin Heidelberg; 2016. 503-12.

15. Adogwa O, Parker SL, Bydon A, Cheng J, Mcgirt MJ. Comparative Effectiveness of Minimally Invasive Versus Open Transforaminal Lumbar Interbody Fusion: 2-year assessment of narcotic use, return to work, disability, and quality of life. J Spinal Disord Tech. 2011;24(8):479-84.

16. Ahn J Park AJ, RossiVJ, Elboghdady I, Bohl DD, Singh R, et al. The Utility of Obtaining Routine Hematologic Laboratory Values Following a Minimally Invasive Transforaminal Lumbar Interbody Fusion. Spine J. 2015;15(10). doi:10.1016/j.spine.2015.07.110.

17. Pelton MA, Phillips FM, Singh K. A Comparison of Perioperative Costs and Outcomes in Patients With and Without Workers' Compensation Claims Treated With Minimally Invasive or Open Transforaminal Lumbar Interbody Fusion. Spine. 2012;37(22):1914-19.

18. Parker SL, Lerner J, McGirt MJ. Effect of Minimally Invasive Technique on Return to Work and Narcotic Use Following Transforaminal Lumbar Inter-body Fusion: a review. Prof Case Manag. 2012;17(5):229-35.

19. Lubelski D, Mihalovich KE, Skelly AC, Fehlings MG, Harrop JS, Mummaneni PV,et al. Is Minimal Access Spine Surgery More Cost-effective Than Conventional Spine Surgery? Spine. 2014:39(22 Suppl1): S65-74.

20. Goldstein CL, Phillips FM, Rampersaud YR. Comparative Effectiveness and Economic Evaluations of Open Versus Minimally Invasive Posterior or Transforaminal Lumbar Interbody Fusion: A Systematic review. Spine. 2016:41 Suppl 8:S74-89.

21. Terman SW, Yee TJ, Lau D, Khan AA, La Marca F, Park P. Minimally invasive versus open transforaminal lumbar interbody fusion: comparison of clinical outcomes among obese patients. J Neurosurg Spine. 2014;20(6):644-52. 